\title{
Ventricular phase analysis moves on to the next phase: What technologists should keep in mind
}

\author{
Keiichiro Yoshinaga, MD, PhD, FACC, FASNC ${ }^{\mathrm{a}}$ \\ a Diagnostic and Therapeutic Nuclear Medicine, National Institute of Radiological Sciences, \\ Chiba, Japan
}

Received May 13, 2020; accepted May 14, 2020

doi: $10.1007 / \mathrm{s} 12350-020-02216-y$

\section{See related article, pp. 1165-1171}

\section{INTRODUCTION}

Ventricular phase analysis to detect cardiac dyssynchrony is a diagnostic technique developed decades ago in the early era of nuclear cardiology. ${ }^{1}$ This basic evaluation tool has been updated as new approaches using cardiac gated SPECT $^{2}$ have been developed to include such along with such clinical aspects as being able to predict or evaluate the effects of cardiac resynchronized therapy (CRT) in patients with heart failure $(\mathrm{HF}) .^{3}$

CRT corrects left ventricular (LV) dyssynchrony in patients who have LV conduction abnormalities. If effective, CRT improves LV function resulting in improved capacity for exercise and possibly improved outcomes. However, about $30 \%$ to $40 \%$ of patients with CRT device implants do not respond to this treatment despite meeting the indication parameters. This limitation has motivated the development of selection criteria regarding appropriate candidates for CRT implantation.

There are three goals of initial assessment: to detect true conduction abnormalities between LV septum and free wall including lateral wall, to detect viable myocardium versus progressed scar tissue, and to determine possible locations for cardiac leads.

\footnotetext{
Reprint requests: Keiichiro Yoshinaga, MD, PhD, FACC, FASNC, Diagnostic and Therapeutic Nuclear Medicine, National Institute of Radiological Sciences, 4-9-1 Anagawa, Inage-Ku, Chiba263-8555, Japan; yoshinaga.keiichiro@qst.go.jp

J Nucl Cardiol 2021;28:1172-4.

$1071-3581 / \$ 34.00$

Copyright (c) 2020 American Society of Nuclear Cardiology.
}

Determining an appropriate lead position can be a challenge. ${ }^{4}$ Therefore, the initial focus of pre-assessment should be to establish the existence of true dyssynchrony and to detect viable myocardium. ${ }^{4}$

Non-invasive cardiac imaging has been useful for these purposes, and research interests have been focused on developing accurate and widely available approaches. In this regard, Echocardiography was one early approach developed, and several techniques involving echocardiography have been proposed. The basic method of confirming LV dyssynchrony is to compare the wall motion between the septum and free wall, mainly the lateral wall. Echocardiography is a daily clinical practice and widely available. However, the quality of data acquisition and images depend on the operator. This is one of the major limitations of echocardiography. CRT has become popular and to date there have been some multi-center trials, including the recent IAEA-sponsored VISION trial. For both research and clinical purposes, we require an approach that is easier and more highly reproducible. What kinds of non-invasive cardiac imaging are suitable for this purpose? Readers of the Journal of Nuclear Cardiology would no doubt say that nuclear cardiology approaches are the best.

\section{WHAT ARE SOME TIPS FOR TECHNOLOGISTS DOING DYSSYNCHRONY ASSESSMENT USING ECG-GATED SPECT?}

As mentioned, ECG-gated SPECT is an established and highly reproducible approach. Currently, almost all data acquisition, data processing and data analysis are automated. We may sometimes not be aware of the background errors or shortcomings. In this issue of the Journal of Nuclear Cardiology, Jimenez-Heffernan et $\mathrm{al}^{5}$ discuss ECG-gated SPECT and note some of the pitfalls of ECG-based standard approaches that technologists should keep in mind, based on the authors' experience in conducting the IAEA-sponsored 
Table 1. Key issues in obtaining good quality phase analysis

\begin{tabular}{|c|c|c|}
\hline Tests & Before scan & Data processing \\
\hline Purpose & $\begin{array}{l}\text { Obtaining sufficient regional radio } \\
\text { counts }\end{array}$ & Obtaining suitable image for phase analysis \\
\hline $\begin{array}{l}\text { Check } \\
\text { list }\end{array}$ & $\begin{array}{l}\text { Look at patient background } \\
\text { Check ECG } \\
\text { Af, VPC, APC, LBBB } \\
\text { Check cardiac function using other } \\
\text { tests }\end{array}$ & $\begin{array}{l}\text { Looking at and check quality of LV contour determined by } \\
\text { automated software } \\
\text { Apply manual ROI setting in case of failure of automated detection }\end{array}$ \\
\hline
\end{tabular}

VISION CRT multi-center trial. ${ }^{6}$ One aim of using ECGgated SPECT is to detect systolic phase differences between the septum and free wall.

\section{BEFORE PERFORMING DATA ACQUISITION}

In this trial, the authors analyzed phase difference using a regional time radioactivity counts curve. Since normal myocardium is $10 \mathrm{~mm}$ thick and scar tissue is thinner than $10 \mathrm{~mm}$, most current SPECT scanners can distinguish between endocardium and epicardium. Therefore, the curve basically comes from the partial volume effects of radioactivity count which increases during systole. Therefore, we need to obtain the highest radioactivity counts possible from each region (Table 1).

The authors address several important issues. From a clinical point of view, it is important to look at a resting ECG prior to data acquisitions. Left bundle branch block (LBBB) is one of the most important indications for CRT. It is known that patients with CRBBB reduced septal wall motion have hyperkinesis in the lateral wall, which leads to two issues: increased LV internal pressure resulting in reduced blood flow and reduced cardiac metabolism. ${ }^{7,8}$ These may be factors in reduced tracer accumulation resulting in lower counts. The authors used either 8 or 16 RR intervals. Considering the accuracy of phase analysis, it would be better to use 16 segments. In my opinion, for this kind of multi-center trial, the leading center should determine the details of parameters.

\section{DATA PROCESSING}

Currently, all ECG-gated SPECT software installed on commercial SPECT scanners automatically processes the ECG-gated imaging data and automatically sets the contour of the LV wall. Since phase analysis involves a very simple algorithm, there should be no variability in automatically calculated data. The RUBY-10 study compared 10 commercial or research-based automated applications for estimating regional myocardial blood flow (MBF). ${ }^{9}$ The model used for such software is rather complex but the data on MBF were consistent among applications that used the same kind of kinetic modeling. However, there were some discrepancies in MBF measurements from various applications. Inconsistent findings were the result of the algorithm related to the region of interest (ROI) setting. There situation would be similar for this phase analysis using ECG-gated software. With all of these software programs, the quality of edge detection has improved. Therefore, during heavy daily clinical practice, we may rely extensively on the automated software and may less frequently look at edge detection. HF patients who have undergone CRT often have damaged myocardium, ${ }^{10,11}$ which results in lower regional radioactivity and makes automated edge detection difficult. In this regard, it is important to look at the results of LV wall trace. The authors also manually applied a base setting using nongated images. Non-gated images have greater radioactivity counts than do gated images, so this approach is also important.

The authors also examined the base selection algorithm based on LV ejection fraction (EF). Setting this algorithm is quite important to standardized image processing in multi-center trials. ${ }^{5}$

After the appropriate LV contour is set, the data including phase analysis, and measurements of myocardial perfusion, LV function and wall thickening become reliable. Even with automated software, there are still many things technologists should do to improve the quality of imaging data. 


\section{Acknowledgments}

The author thanks Natsue Ito, MT for her help writing manuscript. This manuscript has been reviewed by a North American English language professional editor, Ms. Holly Beanlands. The authors also thank Ms. Holly Beanlands for critical reading of the manuscript.

\section{Disclosures}

Keiichiro Yoshinaga has no conflict of interest.

\section{References}

1. Daou D, Lebtahi R, Faraggi M, Petegnief Y, Le Guludec D. Cardiac gated equilibrium radionuclide angiography and multiharmonic Fourier phase analysis: Optimal acquisition parameters in arrhythmogenic right ventricular cardiomyopathy. J Nucl Cardiol 1999;6:429-37.

2. Chen J, Garcia EV, Bax JJ, Iskandrian AE, Borges-Neto S, Soman P. SPECT myocardial perfusion imaging for the assessment of left ventricular mechanical dyssynchrony. J Nucl Cardiol 2011;18:685-94.

3. Moss AJ, Hall WJ, Cannom DS, Klein H, Brown MW, Daubert JP, Estes NA 3rd, Foster E, Greenberg H, Higgins SL, Pfeffer MA, Solomon SD, Wilber D. Zareba W and Investigators M-CT. Cardiac-resynchronization therapy for the prevention of heartfailure events. N Engl J Med 2009;361:1329-38.

4. Yancy CW, McMurray JJ. ECG-still the best for selecting patients for CRT. N Engl J Med 2013;369:1463-4.

5. Jimenez-Heffernan A, Butt S, Mesquita CT. Technical aspects of gated SPECT MPI assessment of ventricular dyssynchrony used in the vision-CRT study. J Nucl Cardiol 2020. https://doi.org/10.10 07/s12350-020-02122-3.
6. Peix A, Karthikeyan G, Massardo T, Kalaivani M, Patel C, Pabon LM, Jimenez-Heffernan A, Alexanderson E, Butt S, Kumar A, Marin V, Mesquita CT, Morozova O, Paez D, Garcia EV. Value of intraventricular dyssynchrony assessment by gated-SPECT myocardial perfusion imaging in the management of heart failure patients undergoing cardiac resynchronization therapy (VISIONCRT). J Nucl Cardiol 2019. https://doi.org/10.1007/s12350-01801589-5.

7. Delgado V, van Bommel RJ, Bertini M, Borleffs CJ, Marsan NA, Arnold CT, Nucifora G, van de Veire NR, Ypenburg C, Boersma E, Holman ER, Schalij MJ, Bax JJ. Relative merits of left ventricular dyssynchrony, left ventricular lead position, and myocardial scar to predict long-term survival of ischemic heart failure patients undergoing cardiac resynchronization therapy. Circulation 2011;123:70-8.

8. Thompson K, Saab G, Birnie D, Chow BJ, Ukkonen H, Ananthasubramaniam K, Dekemp RA, Garrard L, Ruddy TD, Dasilva JN, Beanlands RS. Is septal glucose metabolism altered in patients with left bundle branch block and ischemic cardiomyopathy? J Nucl Med 2006;47:1763-8.

9. Nesterov SV, Deshayes E, Sciagra R, Settimo L, Declerck JM, Pan XB, Yoshinaga K, Katoh C, Slomka PJ, Germano G, Han C, Aalto V, Alessio AM, Ficaro EP, Lee BC, Nekolla SG, Gwet KL, deKemp RA, Klein R, Dickson J, Case JA, Bateman T, Prior JO, Knuuti JM. Quantification of myocardial blood flow in absolute terms using (82)Rb PET imaging: The RUBY-10 Study. JACC Cardiovasc Imaging 2014;7:1119-27.

10. Normand C, Linde C, Blomstrom-Lundqvist C, Stellbrink C, Gasparini M, Anker SD, Plummer C, Sarigul NU, Papiashvili G, Iovev S, Dickstein K. Adherence to ESC cardiac resynchronization therapy guidelines: Findings from the ESC CRT Survey II. Europace 2020. https://doi.org/10.1093/europace/euaa067.

11. Oeing CU, Tschope C, Pieske B. The new ESC guidelines for acute and chronic heart failure 2016 Herz. 2016;41:655-63.

Publisher's Note Springer Nature remains neutral with regard to jurisdictional claims in published maps and institutional affiliations. 